\title{
Sistema de classificação de arquivos em órgãos de fiscalização e controle da Colômbia
}

María Janneth Álvarez Álvarez

Bibliotecária e Arquivista, Universidade de La Salle, Especialista em Arquivologia pela Pontifícia Universidad Javeriana. Mestrado em Ensino pela Universidade de La Salle -Sistemas de Informação do Programa de Ensino, Biblioteca e Arquivo

Pedro Ignacio Galeano Martínez

Bibliotecário e Arquivist, Especialista em Sistemas de Informação e Gestão Documental, Mestrado em Ensino pela Universidade de La Salle. Coordenador da Especialização em Sistemas de Informação e Gestão de Documentos

Julio Alberto Parra Acosta

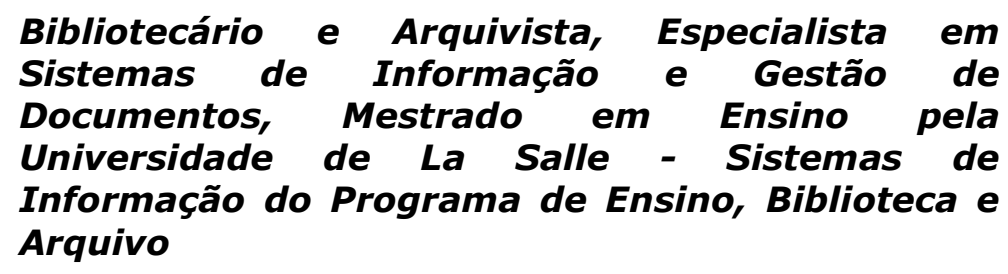

Este artigo surge da pesquisa disciplinar financiada pela Universidade de La Salle - Programa de Sistemas de Informação, Biblioteca e Arquivos -, que teve como objetivo avaliar os sistemas de arquivos de classificação dos órgãos de fiscalização e controle na Colômbia, que, em sua concepção e em conformidade com as diretrizes do Archivo General de la Nación, é um sistema orgânicofuncional. Com base em novas tendências de sistemas de arquivos e classificação e pela necessidade de revitalizar e trazer novas estruturas de classificação para o setor público na Colômbia, sugeriu-se um esquema de plano de classificação cross-funcional, que, no âmbito de órgãos estaduais, adapta-se à dinâmica das mudanças estruturais e de gestão documentária do próprio governo.

Palavras-chave: Classificação documental; Plano de classificação; Sistemas de classificação; Órgãos de controle; Organização de arquivo. 


\section{Archival classification system in control and vigilancy agencies of Colombia}

This article arises from disciplinary research funded by the University of La Salle, Program Information Systems, Library and Archives, which aimed to evaluate the file systems of classification of the supervisory and control in Colombia, which in its conception and in accordance with the guidelines issued by the Archivo General de la Nación, is an organic-functional system. Based on new trends in file systems classification and the need to revitalize and bring new classification structures for the public sector in Colombia, suggested a classification scheme crossfunctional, which, under state agencies, adapts the dynamics of structural changes and management documentaries own government.

Key words: Classification of documents; Classification table; Classification systems; Controlorgans; File organization.

Recebido em 01.08.2011 Aceito em 17.05.2012

\section{Introdução}

Sem dúvida, no contexto latino-americano, o desenvolvimento dos arquivos na Colômbia, com a criação de um órgão de governo, políticas públicas de arquivos, protegidos por um cenário de maior regulamentação e estruturação de um Sistema Nacional de Arquivos, levaram-na a ser um Estado que reconhece os arquivos como fonte legítima para a gestão pública, participação cidadã, controle político e, ainda, com a preservação da memória coletiva da nação.

No entanto, o país não tem estudos regulares e sistemáticas investigações que revelem o grau de propriedade, cumprimento e funcionalidade das políticas, programas e projetos de arquivamento em diferentes níveis, setores e instituições, que são funções do Governo, cujos resultados poderiam trazer um feedback da dinâmica arquivística na Colômbia.

A partir desta perspectiva e como uma contribuição da academia para a realidade arquivística nacional, o presente estudo surgiu da necessidade de se saber o grau de estrutura e funcionalidade do Sistema de Classificação de Arquivos das agências de vigilância e controle na 
Colômbia, a partir de um contexto teórico, fornecido pelo Arquivo Geral da República.

As organizações em estudo foram representadas nacionalmente pela Procuraduría General de la Nación, Auditoria General de la Nación, Contaduría General de la Nación e, no âmbito do distrito, pela Contraloría de Bogotá1; agências cuja função constitucional é a de fiscalização e controle sobre os aspectos fiscais, contábeis e administrativos da administração pública.

A partir da análise dos dados coletados, concluiu-se que o sistema de documentos dessas agências, que operam o sistema de classificação e controle na Colômbia, ocorrem em nível técnico, devido às restrições identificadas pelo Archivo General de la Nación. No entanto, a sua funcionalidade é complexa, no momento da aplicação prática em arquivos institucionais.

\section{Marco teórico}

A classificação dos registros é considerada como uma causa - efeito: a execução das atividades administrativas produzem documentos que são provas de realizações. Portanto, as classes documentais existem a partir do documentário dos próprios criadores: as instituições, escritórios e divisões administrativas que lidam com documentos em prol de suas funções. Neste sentido, a classificação está implícita desde o início (CRUZ MUNDET, 1996).

A complexidade dos sistemas de classificação surge em relação à concepção dos autores do processo, com concepções diferentes. Dupla del Moral (1979) prevê que a classificação "é a operação em que os documentos produzidos e recebidos por uma unidade administrativa específica são separados, formando um conjunto orgânico de documentos relativos às atividades do cargo."

Por sua vez, Heredia (1993) define como "separar ou dividir um conjunto de documentos de criação em classes ou grupos", enquanto Cruz Mundet (2005) vê a classificação como um processo que visa a estruturação de documentos do arquivo de uma entidade, organizando-o em uma estrutura lógica chamada Plano de Classificação e Documentos de Arquivo, o que irá refletir nessas relações, hierarquicamente.

Além disso, Alberch Fugueras (2003) concebeu a sua classificação como parte de uma ciência global - a taxonomia -, considerada como um sistema de categorias para classificar os elementos ou sinais individuais, baseado em semelhanças morfológicas, funcionais ou sociais.

Para o caso colombiano, baseado em consultas com especialistas internacionais de países como França, México e Espanha e, ainda, com o consenso da comunidade arquivística nacional - Comissão de Classificação e Descrição do Sistema Nacional de Arquivos -, o Archivo General de la Nación aprovou a classificação como "a fase de organização dos

\footnotetext{
${ }^{1}$ As denominações das entidades colombianas não foram traduzidas, em respeito à linguagem e aos órgãos estaduais da Colômbia.
} 
documentos, que identifica e estabelece grupos, de acordo com a estrutura orgânico-funcional da entidade produtora (fundo, seção, série e/ou subsérie)" (ARCHIVO GENERAL DE LA NACIÓN, 2006).

De acordo com o acima exposto e para efeitos deste estudo, os pesquisadores concordam que a classificação é essencialmente um processo intelectual, com base em uma estrutura de normas administrativas (unidades, funções e processos) de um produtor individual de identificação, caracterização, agrupamento e nomenamento de um objeto comum chamado "documento", observando-se os princípios universais da disciplina arquivística.

No entanto, a organização e gestão de arquivos exigem a concepção e utilização de ferramentas que facilitem o controle e o acesso às informações contidas nos documentos. O efeito é baseado no desenvolvimento de dois processos básicos: a classificação e a avaliação da documentação (ALVAREZ ALVAREZ et al., 2007; ARANGO ROJAS, 2006; UNIVERSIDAD DE ALICANTE, 2006; SIERRA ESCOBAR, 2006).

Assim, a estrutura de um sistema de classificação pressupõe o cumprimento das condições mínimas, que são reguladas pelo corpo diretivo da função arquivística na Colômbia e apoiadas por escritores renomados, como Schellenberg (1987), Duchein (1985), Tanodi (1968; 1975; 2004) e, mais recentemente, Cruz Mundet (1998; 1999), Heredia (1991; 1993), Alberch Fugueras (2003) e Roberge, (1993) entre outros.

Dentro destas condições, a Lei 594 de 2000 (Lei de Registros Gerais para a Colômbia), prevê, no artigo 22, Arquivamento de processos, que, dentro do conceito de arquivo, deve-se considerar os processos de produção, recebimento, distribuição, organização, etc., o que significa que na sua interpretação prevê a classificação, gestão e descrição, sob a observância dos princípios e critérios arquivísticos.

Nesse sentido, a estrutura de um sistema de classificação de arquivo deve atender:

a) ao respeito pelos princípios de arquivo, proveniência e ordem original. O primeiro é identificar os organismos de produção, que deve ser institucional (fundos de documentos) e administrativa (seções e subseções documentais), em conformidade com a estrutura organizacional da instituição, devidamente aprovada por um ato administrativo; o segundo permite conhecer a ordem na qual os documentos são produzidos para o desenvolvimento de um processo, de acordo com as regras e procedimentos devidamente regulamentados;

b) à criação e nome da série de documentários e subsérie comuns e missionária, em associação com as funções gerais e específicas das unidades organizacionais, devidamente regulamentadas pelos atos administrativos da entidade produtora (GODOY et al. 1995; ARANGO ROJAS, 2006); 
c) à realização de regras gerais e específicas de acordo com a natureza da instituição e a realização dos objetivos, planos, programas e projetos institucionais estratégicos

A pesquisa levou em conta o sistema de classificação orgânicofuncional, validado pelos autores e escritores da disciplina arquivística, de acordo com objetivos desta investigação, para determinar o grau estrutural e funcional desse sistema nos organismos em estudo.

O sistema de classificação orgânico-funcional surgiu em meados dos anos 80. É baseado no agrupamento de conjuntos e subconjuntos de documentos, com os quais atribui-se uma relação direta com as unidades administrativas que responsabilidade com o processamento ou com a resolução da questão. Embora esse sistema esteja plenamente de acordo com o processo de organização de arquivos, possui a desvantagem de sua variabilidade ao longo do tempo, uma vez que os organogramas das entidades são mudados continuamente, por várias contingências, portanto, tornando-o instável.

O resultado da atividade de classificação de uma coleção de documentos é refletido na ferramenta de gerenciamento de documentos, conhecida como Plano de Classificação de Documentos de Arquivo, cuja característica principal é mostrar uma hierarquia de seções, subseções, séries e documentários subconjuntos de uma entidade, permitindo a incluindo novos grupos de documentários e facilitando o seu acesso e controle através de uma estrutura padrão de codificação.

Um plano de classificação de documentos de arquivo, para assumir o seu papel de classificação, deve atender aos seguintes requisitos:

a) dinâmico, ou seja, permitindo a inclusão e exclusão de séries documentais e subséries, de acordo com a evolução orgânica-funcional da entidade;

b) claro, isto é, reflete, com precisão, toda a estrutura administrativa e funcional da entidade;

c) uniforme, ou seja, armazena, com simetria, a denominação e codificação das agrupações documentais.

A figura seguinte (Figura 1) resume os dados que devem ser levados em conta no momento de desenhar e articular os aspetos do Plano de Classificação de Documentos de Arquivo: 
Figura 1 - Contexto do plano de classificação de documentos de arquivo Contexto do Plano de Classificação de Documentos de Arquivo

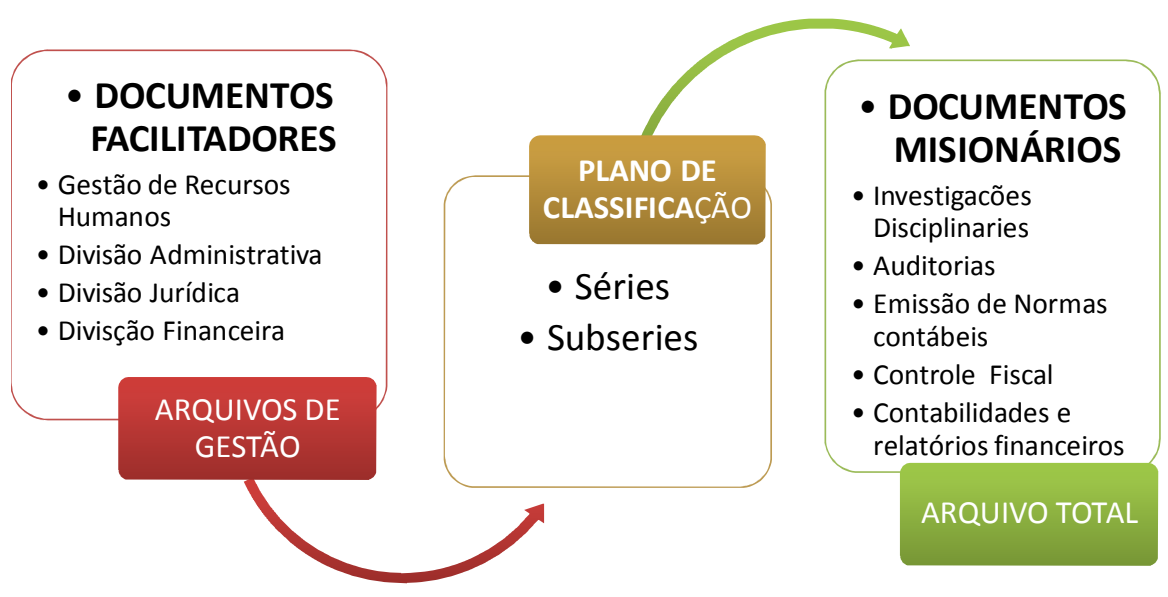

Fonte: Os autores

Os Documentos Facilitadores estão no plano da funcionalidade administrativa, jurídica, contábil e de gestão de pessoal das instituições, por seus valores primários e de relevância maiúscula nos Arquivos de Gestão. No entanto, os Documentos Missionais conservam valores primários e podem ter, de acordo com a avaliação correspondente, valores secundários, pelo sentido histórico, cultural ou patrimonial diante da Nação e da própria instituição produtora.

Neste sentido, o Plano de Classificação de Documentos de Arquivo deve considerar estas duas situações em um Arquivo Total, isto é, a compreensão dos documentos de arquivo como uma unidade que precisa de parâmetros para estabelecer sua organização, descrição e posterior acesso à informação e consulta.

\section{Materiais e métodos}

A investigação foi proposta com o objetivo de conhecer a estrutura do sistema de classificação relativa à Agência de Controle e Fiscalização da Colômbia, através de uma pesquisa descritiva (HERNÁNDEZ SAMPIERE, 2003), pela qual foram analisadas e identificadas características funcionais da documentação do organismo objeto de investigação.

Como instrumentos de coleta de dados, foram utilizados 0 questionário sobre processos de classificação utilizadas nas organizações em estudo e uma entrevista com perguntas fixas (gravadas) (HERNÁNDEZ SAMPIERE, 2003).

A pesquisa foi aplicada em funcionários responsáveis pela gestão de registros, a fim de conhecer a avaliação da prestação de contas e, ainda, a estrutura e função do sistema de classificação em cada uma das 
entidades, de acordo com a aplicação das Tabelas de Temporalidade Documental. A população de cada um das entidades é a seguinte:

- na Procuraduría General de la Nación existem 37 unidades organizacionais, cuja amostra foram selecionadas 4;

- na Auditoría General de la Nación existem 21 unidades organizacionais, com amostra de 11;

- na Contaduría General de la Nación existem 19 unidades organizacionais e a amostra foi de 6; e

- a Contraloría de Bogotá possui 52 unidades organizacionais, cuja amostra foi de 52.

A entrevista semiestruturada foi realizada com cada um dos chefes dos Órgãos de Fiscalização e Controle. Esta entrevista era composta de 10 questões, com o objetivo de reunir informações sobre a formação dos Planos de Classificação de Documentos de Arquivo, a aplicação de Tabelas de Temporalidade Documental e a funcionalidade do sistema de séries e subséries, em cada uma das unidades.

Os resultados obtidos com base na análise e interpretação dos dados coletados são estruturados de acordo com os requisitos do Archivo General de la Nación de Colômbia:

a) respeito pelos princípios arquivísticos;

b) desenvolvimento e descrição das séries documentais e subséries comuns e missionárias;

c) realização e cumprimento da norma geral e particular do setor;

d) funcionalidade do Sistema de Classificação de documentos.

\section{Resultados}

\subsection{Respeito pelos princípios arquivísticos}

Os órgãos de fiscalização e controle na Colômbia, para estruturar seu sistema de classificação de registros, baseiam-se na estrutura organizacional devidamente aprovada pelos atos administrativos emitidos pelo Governo. Confrontando com este aspecto, os respondentes concordaram que os grupos de trabalho criados informalmente e por períodos de tempo não são considerados como parte integrante do esquema de classificação, que, de acordo com as normas do Archivo General de la Nación, são grupos que surgiram na estrutura organizacional não suportados por um ato administrativo e relacionados a uma situação temporária e, por isso, a produção de documentos deve ser anexada à comunicação das informações, cuidadosamente.

Além disso, o estudo permitiu determinar que a classificação de documentos com os princípios da proveniência e da ordem natural é 
cumprida de acordo com 94,5\% dos respondentes (69 servidores públicos), no momento de se aplicar as Tabelas de Temporalidade Documental para gestão de organização de arquivos, em conformidade com o disposto nos artigos 22 e 24, da Lei 594 de 2000 (Ver Gráfico 1).

Gráfico 1 - Implementação da Tabela de Temporalidade Documental

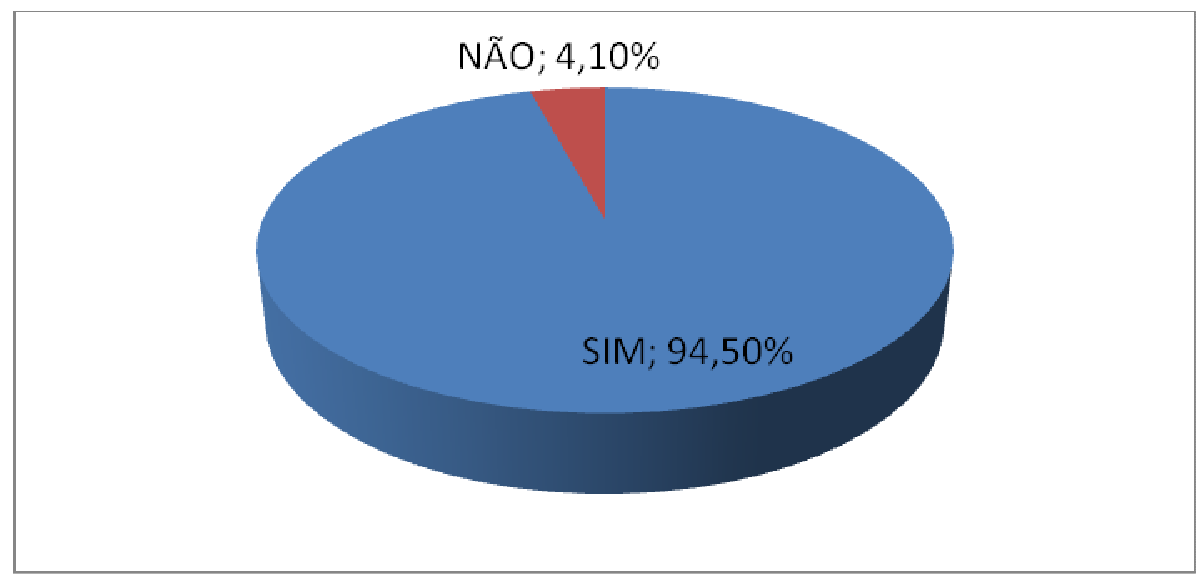

Fonte: Os autores.

Mas, analisando as respostas dos responsáveis pela gestão dos registos das entidades estaduais, verificou-se que existe apatia e, também, negligência dos funcionários públicos na aplicação dos princípios arquivísticos, em relação àqueles estabelecidos nas Tabelas de Temporalidade Documental. Encontraram-se documentos nos arquivos que não correspondem à série e/ou subsérie respectivas, criando novos grupos documentários, requisitando os documentos por data de produção e não para o processamento, incorporando os sistemas de classificação de documentação de apoio à gestão de unidades administrativas, entre outros casos.

\subsection{Estabelecimento e nome da série de documentários e subsérie comum e missionária}

O problema da padronização na criação e nomeação de séries documentais e subséries constitui uma barreira ao entendimento e funcionalidade do sistema de classificação nos Órgãos Nacionais de Vigilância e Controle da Colômbia, pois nem o corpo diretivo do governo, os setores produtivos e de serviços ou, ainda, de arquivos, chegam a um consenso sobre o nome dado à gestão de grupos documentários originados pela gestão do Estado, especialmente daqueles em que a documentação é transversal e de apoio à Administração Pública.

No que diz respeito à designação das séries documentais e subséries, $9 \%$ acreditam que o nome dos grupos documentários está intimamente relacionado ao papel das unidades organizacionais. Para $14 \%$, o procedimento está representado no nome atribuído a cada uma das séries e subséries que compõem a Tabela de Temporalidade Documental. 
O nome das séries e subséries de documentos, na opinião de $73 \%$ dos funcionários públicos, é uma resposta à combinação de funções e procedimentos das unidades administrativas, dos organismos em estudo.

No entanto, $4 \%$ dos entrevistados confirmaram que o nome das séries e subséries documentais não é compatível com a função e procedimento, simplesmente pressupõe a identificação dos provenientes de atividades operacionais e de suporte (Ver Gráfico 2).

Gráfico 2 - Denominação e formação de séries

documentais

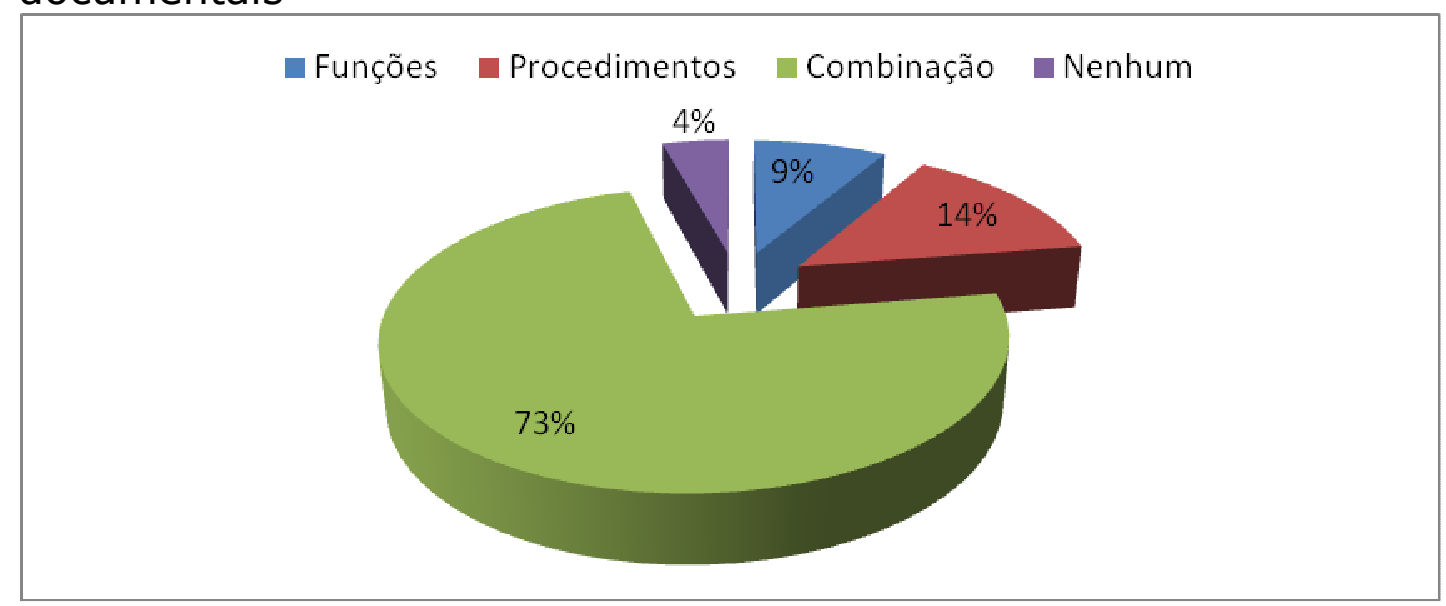

Fonte: Os autores.

A partir desta perspectiva, pode-se inferir que os produtores de documentos não estão envolvidos ativamente na definição dos nomes das séries documentais e subséries, deixando a responsabilidade dessa atividade para os chefes dos arquivos e dos Comitês de Arquivos dos organismos estudados.

\subsection{Realização e cumprimento da norma geral e particular do setor}

A investigação determinou que as regras gerais e específicas aplicáveis ao exercício das funções dos organismos de vigilância e controle não são aplicadas com o rigor exigido para construção de um sistema de classificação de arquivos.

É evidente, na Colômbia, que as regras que regem as funções e os procedimentos de uma agência estatal definem claramente determinados tipos de documentos que devem estar presentes nas ações do governo, contra e para eles, identificando-se uma exigência legal, ou seja, um tipo de documento que deve ser incluído na construção dos Planos de Classificação de Documentos de Arquivo. 


\subsection{Funcionalidade do sistema de classificação de documentos}

É importante notar que a funcionalidade do sistema de classificação nos Órgãos Nacionais de Vigilância e Controle da Colômbia foi analisada a partir de duas perspectivas: a primeira diz respeito à estruturação de arquivo e, a segunda, a partir do ponto de vista de acesso e recuperação da informação.

A funcionalidade do sistema de classificação por séries documentais e subséries na organização de arquivos de gestão das unidades de gerenciamento, objeto deste estudo, para $89,04 \%$ dos entrevistados é prática e atenda às necessidades dos organismos estudados. Entretanto, apenas $11 \%$ ( $3 \%$ acha o que o assunto é indiferente e $8 \%$ acredita que é inadequado) dos funcionários sentem que o sistema de classificação utilizado não é prático, porque dificulta a identificação e criação de séries documentais e subséries, dada a contínua mudança nas estruturas organizacionais e as funções atribuídas às diferentes unidades ou escritórios, como se observa (Gráfico 3).

Gráfico 3 - Funcionalidade do sistema de classificação documental

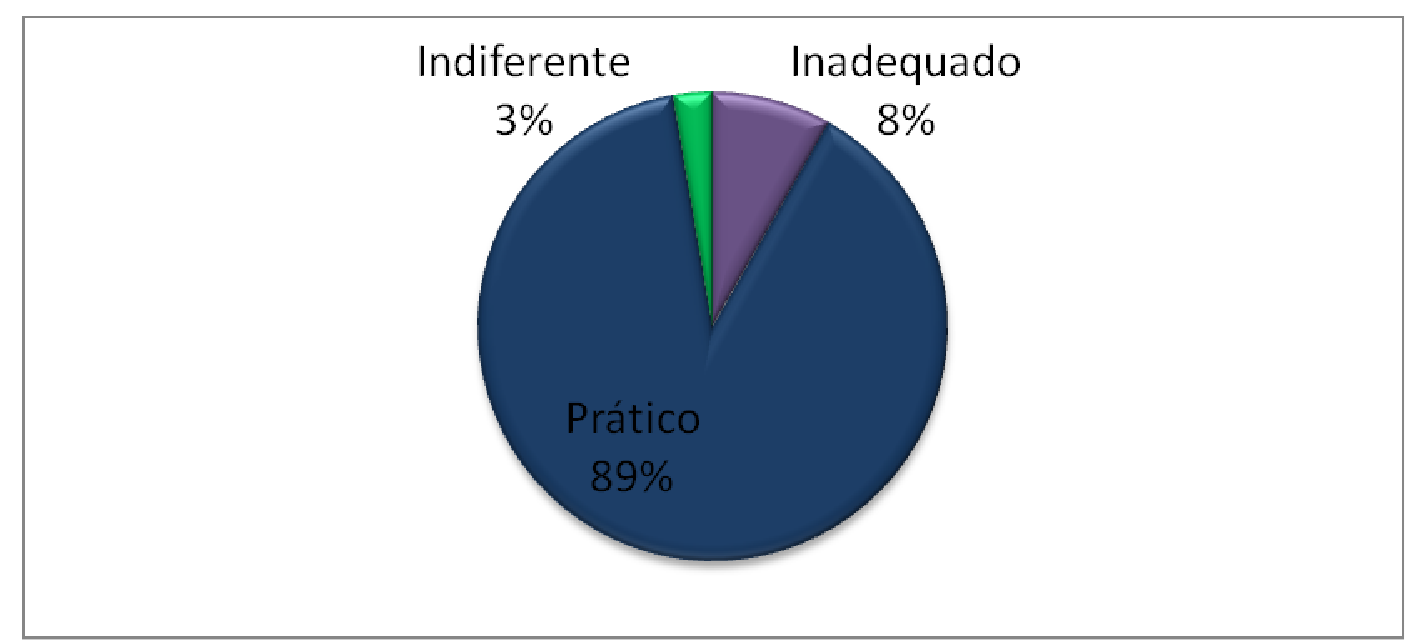

Fonte: Os autores.

Com o entendimento de que um sistema de classificação de arquivo garante a recuperação da informação, $94,5 \%$ dos entrevistados confirmaram que o sistema operacional permite o acesso em tempo real aos documentos de arquivo, no entanto, 5,5\% disseram que para recuperar as informações os tempos são amplos e as exigências para a consulta são dificultadas, como segue: 
Gráfico 5 - Recuperação de Informação

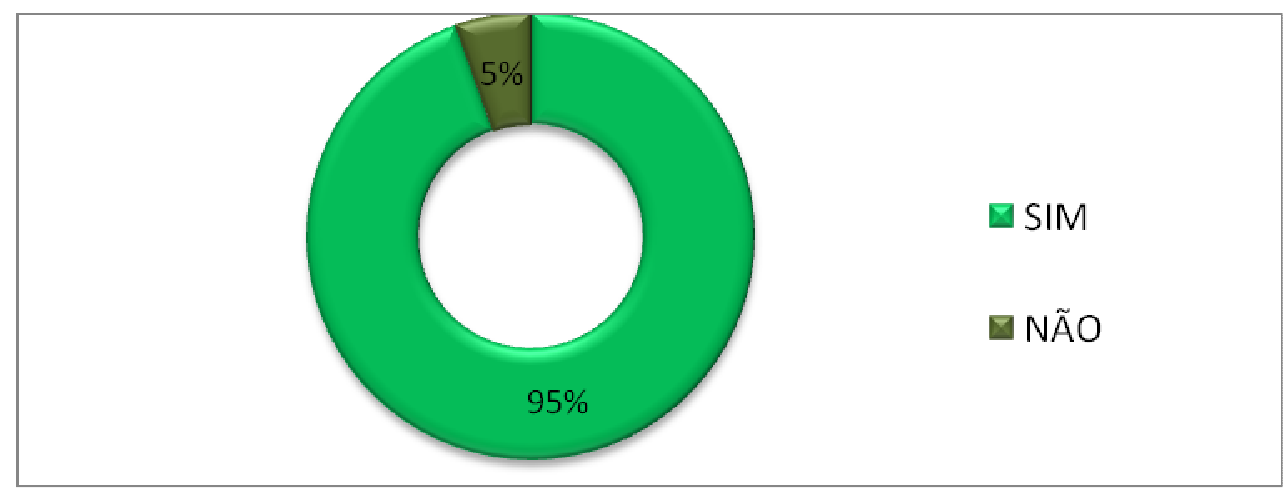

Fonte: Os autores.

\section{Discussão}

A estrutura para o Sistema de Classificação Documental dos Órgãos de Fiscalização e Controle, na Colômbia, reflete a estrutura de um fundo:

a) fundo: um conjunto de documentos produzidos organicamente por uma entidade, cujo nome é identificado (Exemplos: Fundo Documental da Procuraduría General de la Nación, Fundo Documental da Contraloría Distrital de Santa fé de Bogotá);

b) seções: cada uma das divisões principais do fundo, com base nas responsabilidades de cada agência ou unidade organizacional, em conformidade com as leis aplicáveis. (Exemplo: Escritório Geral da Procuraduría General de la Nación, Gabinete de Administração da Contraloría Distrital de Santa fé de Bogotá);

c) subseções: cada uma das agências ou escritórios que compõem a divisão do fundo, que dá funções específicas;

d) série: cada um dos conjuntos de documentos produzidos de acordo com uma mesma atribuição (Exemplo: Contratos, Relatórios); e

e) subsérie: conjunto de documentos resultantes da execução de uma atividade específica. (Exemplo: Contratos de serviços, Contratos de construção, Relatórios de auditoria).

É preciso apontar que a escassa formação de profissionais e de pessoas responsáveis pela implementação dos sistemas de classificação nos arquivos de gestão não incentivam a atualização e fortalecimento dos instrumentos de classificação e avaliação de documentação.

Por isso, a incorporação do estudo sistemático e analítico da lei colombiana que se aplica ao cumprimento das funções gerais e missionárias dos órgãos de fiscalização e controle é imprescindível no processo de estruturação dos sistemas de classificação. 
Além disso, a constante mudança organizacional das instituições do Estado na Colômbia, especialmente levando-se em conta os processos de reestruturação e modernização da administração pública, está buscando alternativas de ação para a classificação de coleções de documentos, especialmente em relação a essas funções que são comuns às agências do governo que possuem Gestores de Recursos Humanos, ligados a diferentes áreas de pessoal, o Secretário-Geral ou Secretário da Divisão de Administração, dependendo da estrutura organizacional da entidade, resolvendo, assim, um processo de constante atualização de seus sistemas de classificação de documentos.

Considerar, também, a inclusão da tipología documental dentro do Quadros de Classificação Documental dos Organismos de Vigilância e Controle, de tal forma que se possa vislumbrar a integridade das estruturas arquivísticas.

A seguir, os dados obtidos, segundo a literatura analisada. Propõese um Plano de Classificação Funcional para séries transversais das organizações em estudo, tendo em conta os seguintes níveis de estrutura:

a) primeiro nível: corresponde às categorias principais que são dadas pelas funções gerais que devem atender os órgãos de fiscalização e controle na Colômbia, da seguinte forma: Gestión Política y de Direccionamiento Organizacional, GestiónFinanciera; Gestión Administrativa, Gestión de PersonaleControl de Gestión2;

b) segundo nível: cada categoria é dividida em classes, que correspondem à série documental, que representa o conjunto de tipos documentais de estrutura homogênea e de conteúdo, a conformidade dos produtos com uma função específica; e

c) terceiro nível: cada classe é dividida em subclasses correspondente às subséries documentais, entendida como um conjunto de unidades documentais que são parte de uma série e precisam classificar de acordo com as funções específicas e ao tratamento de cada caso.

Para cada uma das séries e subséries propostas no Plano de Classificação Funcional, há um código que identifica e que deve ser associado, conforme o caso, para a unidade administrativa, na prática e em conformidade com a estrutura organizacional existente, coma responsabilidade de manter tais informações.

No Anexo 1 se apresenta o Plano de Classificação de Documentos de Arquivo para as séries transversais e subséries nos Órgãos de Fiscalização e Controle da Colômbia, segundo a análise de funções comuns e de acordo com as informações que são registradas no documentário

\footnotetext{
${ }^{2}$ Dadas as características da pesquisa e os órgãos de estudo, não se traduzem os nomes das séries e subséries ou outros elementos próprios da proposta do Plano de Classificação de Documentos de Arquivo para os Órgãos de Fiscalização e Controle da Colômbia.
} 
existentes nos Tabelas de Temporalidade Documental em cada uma das entidades investigadas, devidamente aprovadas pelo Archivo General de la Nación. Nesse sentido, este anexo representa o resultado da investigação, e sua fonte é o trabalho dos autores.

\section{Conclusões}

A pesquisa teve como objetivo investigar a implementação e funcionalidade dos sistemas de classificação de arquivos para os Órgãos Estaduais de Fiscalização e Controle da Colômbia. Através da implementação de uma série de procedimentos e instrumentos, foi possível reconhecer, analisar e interpretar as informações obtidas, para as quais se apresenta as seguintes conclusões:

A análise dos dados obtidos revelaram que os Sistemas de Classificação de Arquivos para os Órgãos Estaduais de Fiscalização e Controle da Colômbia têm como base a estrutura orgânico-funcional, de acordo com os parâmetros estabelecidos pelo Archivo General de la Nación. Isso mostra que as diretrizes de arquivamento e regulamentos têm sido implementadas e assimiladas pelos funcionários responsáveis pela sua aplicação nas organizações em estudo, para dar cumprimento às normas estabelecidas na Lei 594, de 2000.

O Sistema de Classificação que funciona nos Órgãos Estaduais de Fiscalização e Controle da Colômbia satisfazem os critérios e as estruturas administrativas de cada um dos órgãos e funções, que foram atribuídas a diferentes unidades, o que facilita o processo de recuperação e conservação de informações confidenciais.

Esta pesquisa concluiu, também, que a execução da Classificação Documental exige responsabilidade e um amplo conhecimento das normas arquivísticas e do funcionamento da instituição, mostrando que o apoio de cada um dos diretores dos arquivos dessas instituições é constante, em conformidade com os processos de organização de arquivos em diferentes fases, tanto na classificação quanto no arranjo e descrição.

Os resultados indicaram que um bom sistema de classificação documental beneficia a gestão de uma unidade organizacional, uma vez que está em constante comunicação com outros sistemas que fazem parte das estruturas organizacionais das instituições, que, neste caso, tinha uma característica de supervisão da gestão da política e da administração do Estado. As mudanças na informação trouxeram diferentes cenários que enfatizam a nova aprendizagem no contexto de arquivamento e, dentre esses aspectos, o tema classificação de arquivos, o que, sem dúvida, contribui para o fortalecimento das práticas profissionais colombianas e para a definição de modelos coerentes que facilitam a geração de autoconhecimento.

Diante de isso, a reestruturação e a dinâmica nos estados e departamentos governamentais que estão em linha com os modelos e políticas internacionais, sugere-se a criação de alternativas à ordem estabelecida para modernizar, racionalizar estruturas, para que a 
classificação funcional de documentos possa se tornar uma alternativa fácil de regimes de organização documental.

Nesse ponto, as tendências na administração pública, os sistemas de gestão da qualidade e as abordagens de gestão do conhecimento, exigem mudanças nos processos, estruturas e funções, o que leva a repensar as teorias tradicionais de arquivos e propor novas soluções alternativas para documentação, além de outras posições acadêmicas.

Isso representa a aplicação de uma nova classificação no âmbito do "funcional" para a documentação das entidades com características similares, no caso colombiano, para facilitar os princípios de organização e, assim, identificar os níveis para responder às necessidades de gestão nas áreas de gestão, administração, finanças, recursos humanos, entre outros.

Finalmente, o sistema de classificação funcional representa uma série de benefícios para as organizações, quando contextualizada de uma forma mais simplificada, em estruturas rígidas de processos desenvolvidos em instituições com características semelhantes àquelas que foram objeto do presente estudo ou estruturas similares para lidar com a transformação tecnológica e de comunicação dos arquivos, com a tecnologia da informação e de documentação.

\section{Agradecimento especial:}

A Mery Alexandra Cáceres Arias, licenciada no Espanhol e Letras Clássicas da Universidade Nacional de Colombia, para sua orientação de verificador de estilo.

\section{Referências}

ALBERCH FUGUERAS, R. Los archivos, entre la memoria histórica y la sociedad del conocimiento. Barcelona: UOC, 2003.

ÁLVAREZ ÁLVAREZ, M. et al. Hacia una funcionalidad del sistema de clasificación de archivos en organismos de vigilancia y control de Colombia: una propuesta de investigación. CODICE. Revista de la Facultad de Sistemas de Información y Documentación, v. 3, n. 1, p. 63$71,2007$.

ARANGO ROJAS, A. La identificación de series documentales mediante la gestión por procesos: caso aplicado al sistema de alertas tempranas de la Defensoría del Pueblo. Especialización en Sistemas de Información. Universidad de La Salle. 2006.

- Pautas para la organización de archivos municipales. Bogotá: EI Archivo, 2000

. Cartilla de Clasificación Documental. Bogotá: El Archivo, 2001. 
Bogotá. Memorias: Los archivos y el control social. Archivo General de la Nación de Colombia/División de Programas Especiales. Bogotá: El Archivo. 2003

. Fondos acumulados: manual de organización. 2004. Bogotá: El Archivo, 2004.

. Acuerdo 027 de 2006. Bogotá: El Archivo, 2006.

AUDITORIA GENERAL DE LA NACIÓN. Página institucional. Disponível em: <http://www.auditoria.gov.co>. Acesso em: 17 sept. 2007.

ARÉVALO JORDÁN, V. Diccionario de términos archivísticos. Buenos Aires: Del Sur, 2003

ARCHIVO DE BOGOTÁ D. C. Página institucional. Dsiponível em: <http://www.bogota-dc./>. Acceso em: 12 out. 2007.

BRAVO RIVERA, C. et al. Modelos de cuadros de clasificación funcional de series misionales para la banca comercial-oficina y para las compañías aseguradoras. [s. l.]: Sistemas de Información y Documentación. 2007.

CONTADURÍA GENERAL DE LA NACIÓN. Página institucional. Disponível em: <http://www.contaduria.gov.co/>. Acesso em: 12 out. 2007

CONTRALORÍA DE BOGOTÁ D. C. Página institucional. Disponível em: <http://www.contraloriabogota.gov.co/>. Acesso em: 12 de Out. 2007

CRUZ MUNDET, J. Información y documentación administrativa. Madrid: Techaos, 1998.

Ruipérez, 1999.

COLOMBIA. Ley General de Archivos. Ley 594, de14 de julo de 2000. Disponível em: <http://www.archivogeneral.gov.co/?idcategoria=2023>. Aceso em: 14 out. 2007.

DUCHEIN, M. El respeto de los fondos en Archivística: principios teóricos y problemas prácticos. In: WALNE, P. (Rec.). La administración moderna de archivos y la gestión de documentos: el prontuario RAMP. Paris: Unesco, 1985. p. 69-92.

DUPLA DEL MORAL, A. Manual de archivos de oficina para gestores: comunidad de Madrid. Madrid: Marcial Pons, 1977.

ESPAÑA. Ministerio de Educación y Cultura y Archivo General de La Nación. Grupo Iberoamericano de tratamiento de Archivos administrativos: hacia un diccionario de terminología archivística. Bogotá: Archivo General de la Nación, 1997. 140 p. 
ESTEBAN NAVARRO, M. Fundamentos epistemológicos de la Clasificación Documental: manual de Clasificación Documental. Madrid: Síntesis, 1999.

FERNÁNDEZ GIL, P. Manual de organización de archivos en las oficinas municipales. Granada: Adhara, 1995.

GALLEGO DOMÍNGUEZ, O. et al. Introducción a la Archivística. Bilbao: Departamento de Cultura y Turismo, Gobierno Vasco, 1989.

GODOY DE LOZANO, J. et. al. Organización de documentos de archivo. Bogotá: Imprenta Nacional, 1995.

GUTIÉRREZ, C. et. al. Algunas nociones de archivología: Aurelio Tanodi. Lima: Fondo Prearchivo, 2004.

HERNÁNDEZ SAMPIERE, R. et al. Metodología de la investigación. 4 ed. México: Mac Graw Hill, 2003.

HEREDIA, A. H. Archivística general: teoría y práctica. Sevilla: Diputación Provincial, 1993.

- Clasificación y ordenación. En: GUTIÉRREZ MUÑOZ, César. Archivística: materiales de enseñanza de la Facultad de Letras y Ciencias Humanas. Lima: Pontificia Universidad Católica del Perú, 1991. p. 106123.

JAEN GARCÍA. L. El sistema nacional de información archivística como modelo de unificación de archivos. Universidad de Costa Rica, 2006.

LERMA GONZÁLEZ, H. Metodología de la Investigación. Bogotá: Ecoe, 2004. 166 p.

LÓPEZ GÓMEZ, P. Comisión Técnica de Archivos históricos de la ANABAD. Madrid: ANABAD, 1994.

LLANSO I SANJUÁN, J. Gestión de documentos: definición y análisis de modelos. Euskadi: Irargui, 1997. 250 p.

MARTÍN-POZUELOS CAMPILLOS, M. La construcción teórica en archivística: el principio de procedencia. Madrid: Universidad Carlos III, 1996.

MEMORIAS: Los archivos y la administración pública. In: SEMINARIO DEL SISTEMA NACIONAL DE ARCHIVOS. Anaes... Santafé de Bogotá: Archivo General de la Nación de Colombia, 1998.

MÉNDEZ ÁLVAREZ, C. Metodología: diseño y desarrollo del proceso de investigación. 3. ed. Bogotá: McGraw Hill, 2001.

MONTEJO, A. La clasificación de fondos archivísticos administrativos. Métodos de Información, v. 4, n. 17-18, p. 50-58, 1997. 
NATIONAL ARCHIVES OF AUSTRALIA. Overview of Classification Tools for Records Management. Disponível em: <www.naa.au>. Acesso em: 14 out. 2003.

PINTO, M. et al. Hacia una teoría integradora de la clasificación documental. In: MANUAL de Clasificación Documental. Madrid: Síntesis, 1998.

PROCURADURÍA GENERAL DE LA NACIÓN. Página institucional. Disponível em: <http://www.contaduria.gov.co/>. Aceso em: 14 out. 2007.

REINO UNIDO. Records Manual 2006. Disponível em: $<$ www.dnrintra.state.il.us//rules/RecordsMgt.htm $>$. Acesso em: 21 out. 2007.

ROBERGE, M. La gestió de documents administrtius. Barcelona: Diputación de Barcelona, 1993.

SIERRA ESCOBAR, L. Consideraciones generales sobre Cuadros de Clasificación Documental. Revista Códice, v. 2, n. 2, p. 83-93, 2006.

TANODI, A. Guía de los archivos de Córdoba. Córdoba: Universidad Nacional de Córdoba, Dirección General de Publicaciones, 1968.

- Manual de archivología. Córdoba: Centro Interamericano de Formación de Archiveros, 1975.

2004.

Algunas nociones de archivología. Lima: Fondo Pro Archivo,

SCHELLENBERG, T. Archivos modernos: principios y técnicas. México: Archivo General de la Nación de México, 1987.

UNIVERSIDAD DE ALICANTE. Manual de organización de archivos de oficina. 2006. Disponível em: $<$ www.ua.es/es/bibliotecas/archivo generaln/normativan/manual_organiz ación archivohtml>. Acesso em: 15 out. 2007.

\title{
ANEXO 1 - PROPOSTA DO PLANO DE CLASSIFICAÇÃO FUNCIONAL DE DOCUMENTOS DE ARQUIVO PARA OS ÓRGÃOS DE FISCALIZAÇÃO E CONTROLE DA COLÔMBIA
}

\author{
REPUBLICA DE COLOMBIA \\ UNIVERSIDAD DE LA SALLE \\ FACULTAD CIENCIAS ECONOMICAS Y SOCIALES \\ PROGRAMA DE SISTEMAS DE INFORMACION, BIBLIOTECOLOGIA Y \\ ARCHIVISTICA
}




\section{CUADRO DE CLASIFCACION FUNCIONAL PARA ORGANISMO DE VIGILANCIA Y CONTROL} (SERIES Y SUBSERIES TRANSVERSALES)

\section{SECCIONES- FUNCION GENERICA (PRIMER NIVEL)}

CODIGO

SERIES - FUNCION ESPECIFICA (SEGUNDO NIVEL)

SUBSERIES - ESPECIFICA - ACTIVIDAD (TERCER NIVEL)

GESTION POLITICA Y DE DIRECCIONAMIENTO ORGANIZACIONAL

10

PLANES

1001

Planes Estratégicos

1002

Planes Indicativos

1003

Planes de Acción

20

\section{RESOLUCIONES}

30

\section{DIRECTIVAS}

40

CIRCULARES

4001

Circulares Reglamentarias

4002

Circulares Informativas

50

MANUALES

5001

Manuales de Procesos y Procedimientos

5002

Manuales de Funciones

5003

Manuales de Indicadores de Gestión 
60

ESTUDIOS TECNICOS SECTORIALES

70

CONCEPTOS MISIONALES

ESTION ADMINISTRATIVA

80

CONTRATOS

8001

Contratos con Formalidades Plenas

8002

Contratos sin Formalidades

90

CONVENIOS

100

PROCESOS JUDICIALES

110

PROCESOS ADMINISTRATIVOS

120

PROYECTOS DE INVERSION

\author{
130 \\ PROGRAMAS \\ 13001 \\ Programas de Capacitación \\ 140 \\ INFORMES \\ 14001 \\ Informes de Gestión \\ 14002 \\ Informes a Entidades de Control \\ 14003 \\ Informes Especializados
}




\title{
150 \\ INVENTARIOS
}

15001

Inventarios de Bienes Muebles

15002

Inventarios de Bienes Inmuebles

160

PROGRAMAS GENERALES DE COMPRAS

170

HISTORIAL DE VEHICULOS

180

ACTAS

18001

Actas Comité Directivos

18002

Actas Comité de Control Interno

18003

Actas Comité Paritario de Salud Ocupacional

18004

Actas Comisión de Personal

18005

Actas Comité de Adquisiciones y Licitaciones

\author{
18006 \\ Actas Comité de Compras \\ 18007 \\ Actas Comité de Archivo \\ 190 \\ CONSECUTIVO DE COMUNICACIONES \\ 200 \\ INSTRUMENTOS DE DESCRIPCION
}


TRANSFERENCIAS DOCUMENTALES

220

ESTADISTICAS DE ACTUACION PROCESAL GESTION FINANCIERA

\author{
230 \\ ANTEPROYECTO DE PRESUPUESTOS
}

240

COMPROBANTES CONTABLES

250

LIBROS CONTABLES

\author{
25001 \\ Libro Diario \\ 25002 \\ Libro Mayor y Balances
}

25003

Libros Auxiliares

260

LIBROS DE TESORERIA

26001

Libros Auxiliares de Cajas

26002

Libros Auxiliares de Bancos

270

LIBROS DE REGISTRO PRESUPUESTAL

280

CONCILIACIONES BANCARIAS

290

POLIZAS DE SEGURO

300

ORDENES DE PAGO

GESTION DE PERSONAL 
HISTORIAS LABORALES

320

NOVEDADES DE NOMINA

CONTROL DE GESTION

330

PLANES INTERNOS DE AUDITORIA

340

INFORMES DE AUDITORIA 